\title{
Study of Jet Flow and Dust Motion in Flat Chambers Based on Theory of Gas-Soild Two Phase Flow
}

\author{
Xiaodong Wang ${ }^{1,2}$, Kepeng Hou ${ }^{1,2}$, Jie Liu ${ }^{1,2^{*}}$ and Xiaoyun Wang ${ }^{3}$ \\ ${ }^{1}$ Faculty of Land Resources Engineering, Kunming University of Science and Technology, \\ 650093 Kunming, China \\ ${ }^{2}$ Postdoctorate Station of Mining Industry Engineering, Kunming University of Science and \\ Technology, Kunming, China \\ ${ }^{3}$ College of Civil Engineering, Tongji University, 200 082, Shanghai, China
}

Email: liujie19860809@qq.com

\begin{abstract}
This research aimed to reduce excessive dust concentration in flat chambers and to explore the main factors affecting dust motion. Based on the theory of gas-solid two phase flow and airflow field, a physical model was established. Numerical simulation results of dust concentration distributions in flat chambers, which came from fluent, fluid mechanics computational software, were basically concordant with experimental data. Research results showed the following aspects. (1) The main factors affecting dust motion in flat chambers laid in the jet flow zone and reflux zone. (2) When mean flow velocity in flat chambers ranged from 1.0 $\mathrm{m} / \mathrm{s} \sim 3.0 \mathrm{~m} / \mathrm{s}$, increases in the mean flow velocity resulted in decreases in dust concentration. (3) With the increase in distance away from working faces, air flow velocity and dust concentrations undulated and appeared to have a downward trend in cross sections. Circulation between the jet flow and reflux resulted in the elimination of dust in flat chambers.
\end{abstract}

Keywords: Flat chamber, Dust motion, Jet flow zone, Reflux zone, Gas-solid two phase flow.

\section{INTRODUCTION}

In mine operations, flat chambers refer to large area stopes where the height of a stope is similar to intake airways, and the width of a stope is much wider than that of intake airways. In narrow vein mining operations through room-and-pillar method and thick orebody mining operations through the shrinkage mining method, the existence of flat chambers is common. Air flows into flat chambers from intake airways and becomes the main air flow, whose volume gradually increases between intake airways and exhaust airways. In flat chambers, dust from blasting, instead of being directly taken out by the main air flow, is gradually exhusted through the flow induced by the main air flow. Compared with ventilation in roadways, flow components in flat chambers are complex and ventilation processes require far more time. In short, ventilation of flat chambers is the most difficult aspect in a mine's ventilation system [1-2]. Blasting is a requisite in mining underground resources. However, heavy dust resulting from blasting would damage miners' health and deteriorate underground working conditions. Due to the irregular geometry of flat chambers, constantly changing workplace locations, sophisticated flow field distributions and pollution distributions [3], the improper design of a ventilation system would result in long-term high concentrations of dust after blasting, which would affect the overall mining process.

Based on the gas-solid two phase flow theory, a great deal of research has been conducted on dust motion in air flow [412]. From the 1950s to 1970s, Owen, Lin, Friendlander, Beal et al [13-15], researched dust sedimentation in drifts turbulence. Based on experimental results and taking gravity, molecular diffusion and turbulence diffusion into consideration, mathematical models on dust sedimentation in drifts turbulence was established. Y. M. Wang et al. [16] discovered that air flow components and processes of dust exhaust varied greatly between flat chambers and drifts. Research has pointed out that analysis of the dust exhaust process in chambers must be based on jet confirmed theory. The team also determined processes of dust exhaust in flat chambers and a calculation method of flow rate. Z. G. Jiang et al [17], applied the gas-solid two phase flow theory to simulate dust diffusion processes, in which the standard k-s turbulence model was applied in the gas phase, and the particle cloud model was applied in the solid phase. These research projects and related methods were meaningful in reducing dust concentration. However, in the field of unsteady dust motion and dust concentration distributions in flat chamber blasting faces, research is relatively rare. If a principle of dust exhaust in flat chamber blasting faces can be determined and dust mass concentration and motion 
characteristics can be found, design parameters of ventilation could be set.

The study to explore methods of reducing dust concentration in flat chamber blasting faces could improve underground working conditions and protect miners' health.

\section{VENTILATION IN FLAT CHAMBERS}

In flat chambers, jet flow velocity and areas of jet flow cross sections both increased. Jet flow rate reached the highest value at a certain distance. The total jet flow rate included two major portions. One portion was exhausted from exhaust airways, which was equal to the original intake flow rate from intake airways. The remaining portion, which was induced by original jet flow, gradually changed into reflux from the highest flow rate cross section. The increased flow rate in jet flow and the reflux flow formed circulation flow inside the chambers, which linked up the main flow zone and reflux zone.

Different sets of intake airways and exhaust airways resulted in different forms of jet flow, including symmetrical jet flow, asymmetrical jet flow and a combination of jet flow and stream tube. These various forms directly influenced ventilation effects and flow velocity in chambers. According to research [20], in different forms of flat chambers, requisite flow velocity in blasting dust exhaust could be calculated by the following formula (1):

$Q=4.6 \frac{j V}{K t} \lg \frac{500 A}{V}$

$Q$ represents the flow rate in the flat chamber, $\mathrm{m}^{3} / \mathrm{s} . j$ represents volume ratio between the larger side chamber volume and total chamber volume. In symmetrical jet flow chambers, $j=0.5$, in asymmetrical jet flow chambers, $j=0.5 \sim 1.0$, in jet flow and stream tube combined chambers, $\mathrm{j}=1.0 . \quad V$ represents chamber volume, $\mathrm{m}^{3} . A$ represents explosive mass, $\mathrm{kg} ; K$ represents turbulence diffusion coefficient, based on geometry of the larger side chamber. The geometry includes chamber length, intake airway area, a half width of intake airways and air flow components coefficient, which is 0.07 in a circular jet, and is 0.1 in a flat jet.

\section{GAS-SOLID TWO PHASE GOVERNING EQUATION [21]}

(1) Gas continuity equation:

$\frac{\partial\left(\varphi_{g} \rho_{g} u_{g i}\right)}{\partial x_{j}}=0$

(2) Solid continuity equation:

$$
\frac{\partial\left(\varphi_{p} \rho_{p} u_{p i}\right)}{\partial x_{i}}=0
$$

(3) Gas momentum equation:

$$
\begin{aligned}
& \frac{\partial\left(\varphi_{g} \rho_{g} u_{g i} u_{g i}\right)}{\partial x_{j}}=\frac{\partial}{\partial x_{j}}\left[\mu_{e}\left(\frac{\partial u_{g i}}{\partial x_{j}}+\frac{\partial u_{g j}}{\partial x_{i}}\right)\right] \\
& +\varphi_{g i} \rho_{g} g_{i}-\varphi_{g} \frac{\partial p}{\partial x_{i}}+\beta_{i}\left(u_{p i}-u_{g j}\right)
\end{aligned}
$$

(4) Solid momentum equation:

$$
\begin{aligned}
& \frac{\partial\left(\varphi_{p} \rho_{p} u_{p i} u_{p i}\right)}{\partial x_{j}}=\frac{\partial}{\partial x_{j}}\left[\mu_{p}\left(\frac{\partial u_{p i}}{\partial x_{j}}+\frac{\partial u_{p j}}{\partial x_{i}}\right)\right] \\
& +\varphi_{p} \rho_{g} g_{i}-\varphi_{p} \frac{\partial p}{\partial x_{i}}+\beta_{i}\left(u_{p i}-u_{g j}\right)
\end{aligned}
$$

In the equations, $\varphi_{g} 、 \varphi_{p}$ separately represent gas volume fraction and solid volume fraction, $\varphi_{g}+\varphi_{p}=1 ; u_{g i}$ and $u_{g j}$ separately represent velocity components of gas in $i$ and $j$ directions, m/s. $u_{p i}$ and $u_{p j}$ represent velocity components of particle in $i$ and $j$ directions, $\mathrm{m} / \mathrm{s}$. $\mu_{e}$ represents gas viscosity, Pa $\bullet$, $\mu_{e}=\mu+\mu_{i}$, in which $\mu$ represents gas shear viscosity, $\mu=17.9 \times 10^{-6} \mathrm{~Pa} \cdot \mathrm{s}, \mu_{i}=c_{\mu} \varphi_{g} \rho_{g} \kappa^{2} / \varepsilon, c_{\mu}$ is a constant, $\kappa$ is turbulence kinetic energy, $\varepsilon$ is turbulence dissipation. $\mu_{p}$ represents particle turbulence viscosity, Pa $\bullet$ s. $\rho_{g} 、 \rho_{p}$ separately represent gas phase density and particle phase density, $\mathrm{g} / \mathrm{cm}^{3} . g_{i}$ represents gravity component in $i$ direction, $\mathrm{m} / \mathrm{s}^{2}$. $P$ represents collisional pressure, $\mathrm{Pa} . \beta_{i}$ represents resistance coefficient in $i$ direction.

\section{NUMERICAL SIMULATIONS}

\subsection{Geometry model}

As Figure 1 shows, numerical simulations were based on mines in Yunnan Provence, China. According to working conditions in the flat chamber, software GAMBIT was applied in geometry modeling and meshing, and dust motion in blasting faces were simplified. In the model, the intake airway was a basket handle arch with $4.5 \mathrm{~m}$ width, $4.375 \mathrm{~m}$ height, $2.875 \mathrm{~m}$ whist height, $1.5 \mathrm{~m}$ arch height and $18.24 \mathrm{~m}^{2}$ cross section area. The geometric size of the flat chamber was $60 \mathrm{~m}$ length, $20 \mathrm{~m}$ width and $5 \mathrm{~m}$ height. Explosive consumption per blasting was $100 \mathrm{~kg}$. Duration of ventilation was set as $2400 \mathrm{~s}$. In simulations, air flow velocity in the intake airway was $0.5 \mathrm{~m} / \mathrm{s}$ and pressure was $101 \mathrm{kPa}$.

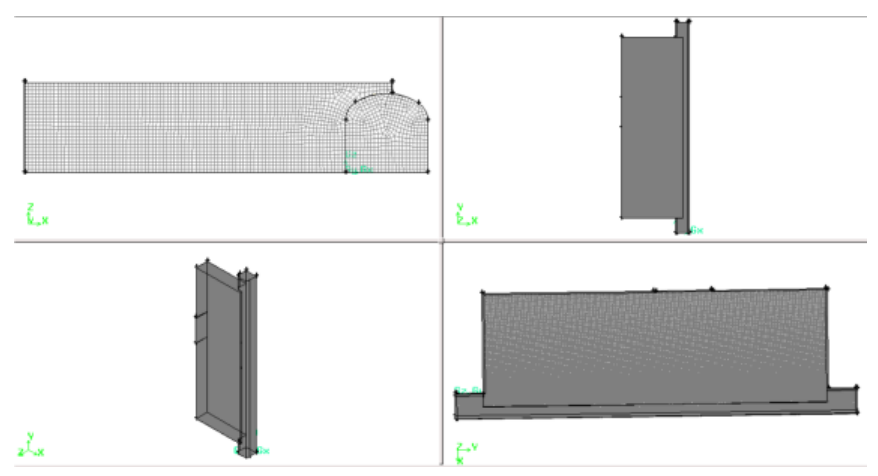




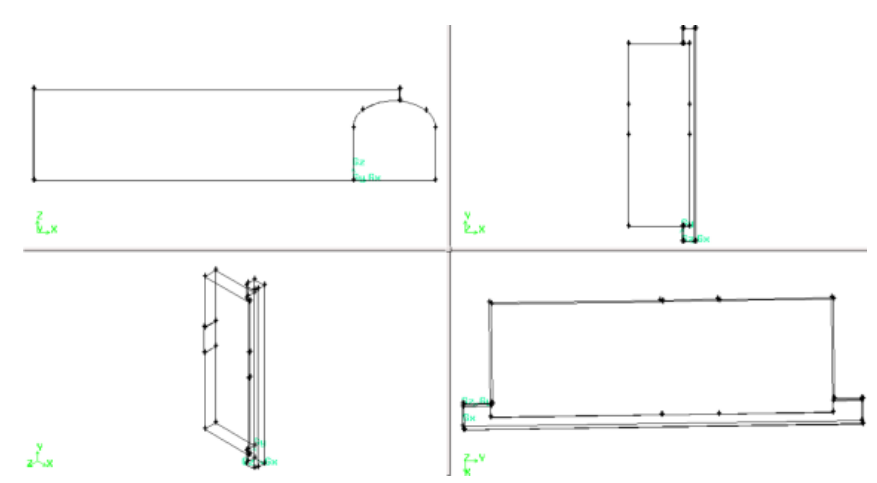

Figure 1. Geometric model of flat chambers

\subsection{Boundary conditions}

Based on the main influencing factors, following assumptions were made. Firstly, since compared with $Q_{b}$ (dust from rock blasting), $Q_{d}$ (dust from crushed falling rock) and $Q_{w}$ (dust arisen from surface of ground and rocks) were relatively small, $Q_{d}$ and $Q_{w}$ were neglected and $Q_{b}$ was taken in consideration in the models. Secondly, the $\mathrm{X}$-axis was perpendicular to the working faces and the positive direction pointed towards the chamber. Dust velocity parallel to the $\mathrm{X}$ axis was $6 \mathrm{~m} / \mathrm{s}$ and dust velocity parallel to the Y-axis and Zaxis both both $0 \mathrm{~m} / \mathrm{s}$. Thirdly, dust appeared instantly in blasting and then diffused.

After setting boundary conditions, meshes generated in software GAMBIT was imported into software Fluent for defining parameters, which are listed in Table 1.

Table 1. Defining parameters in calculation model

\begin{tabular}{l|l}
\hline Boundary conditions & Define \\
Solver & Segregated \\
Viscous model & Kepsilon \\
Energy & Velocity-inlet \\
Inlet Boundary type & $1.0 \mathrm{~m} / \mathrm{s}$ \\
Inlet velocity magnitude & \\
& $4.4998 \mathrm{~m}$ \\
Hydraulic diameter & $3.31 \%$ \\
Turbulence intensity & Outflow \\
Outlet boundary type & On \\
Discrete phase model & 10 \\
Number of continuous phase iterations & \\
per DPM Iteration & \\
& \\
Drag law & Spherical \\
Injection type & Surface \\
Material & Sior \\
Density & $2320 \mathrm{~kg} / \mathrm{m}^{3}$ \\
Diameter distributions & Rosin-Rammler \\
Spread parameter & 2.24 \\
Total flow velocity & $0.12 \mathrm{~kg} / \mathrm{s}$ \\
Turbulence dispersion & Stochastic tracking \\
DPM condition & Trap, Reflect \\
Shear condition & No slip \\
\hline
\end{tabular}

\subsection{Flow field distributions}

According to formula (1), the minimum requisite flow velocity in flat chambers was $0.6 \mathrm{~m} / \mathrm{s}$. When flow velocity in intake airways was at $0.6 \mathrm{~m} / \mathrm{s}$, flow field distributions in the flat chamber were simulated based on software Fluent. Result of flow field distributions are shown in Figure 2.
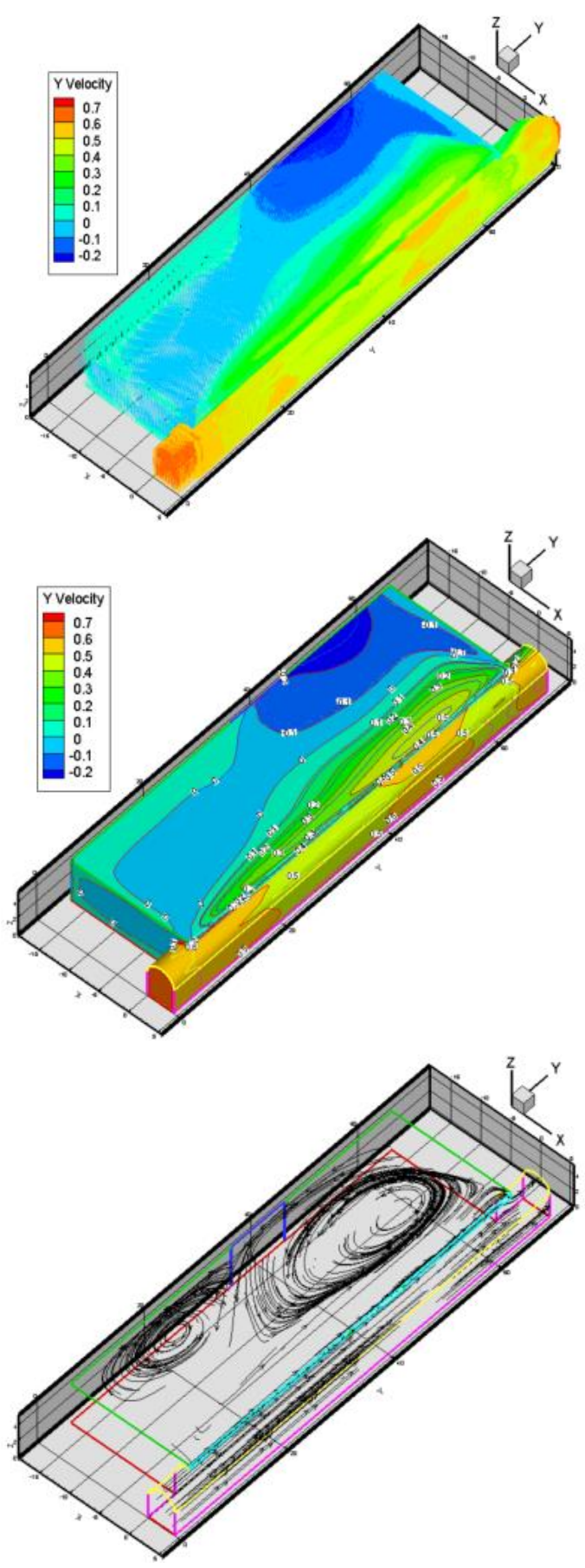

Figure 2. Distributions of flow field and flow velocity in flat chambers

It was observed that

(1) In ventilation processes, due to the restriction of drift sidewalls, the flow near the drift sidewalls showed characteristics of tube flow. In the other side, without the restriction of a sidewall, the boundary of flow expanded and flow rate and increased gradually while flow velocity decreased. On this side, the characteristics of flow were similar to jet flow.

(2) The circulation flow could be divided as two portions according to the jet boundary. One portion, within the boundary, was jet flow heading directly from intake airways towards exhaust airways. The other portion, outside the boundary, was reflux flow, where exhaust of dust mainly 
depended on circulation between jet flow and reflux flow. Compared with the main flow zone, processes of dust exhaust in the reflux zone took much more time.

(3) Flow velocity in different cross sections perpendicular to jet flow axis showed a downward trend from $0.6 \mathrm{~m} / \mathrm{s}$ to 0.1 $\mathrm{m} / \mathrm{s}$. The corner of lee side in chamber was the most difficult zone in chambers to ventilate, where there was faint and local circulation flow. In the zone near the exhaust airways, flow velocity and the change rate of flow velocity were both high and rose when approaching to exhaust airways. These features were consistent with flow field and velocity distributions in mines, which proved that assumptions and parameters were appropriate and numerical simulation was reasonable.

\subsection{Numerical simulations of dust concentration and ventilation time}

As Table 1 shows, parameters of sources of dust were set in a discrete phase model, in which 12,500 particles were randomly produced in blasting. When flow velocity in the intake airways was $1.0 \mathrm{~m} / \mathrm{s}$, dust concentration distributions was recorded.

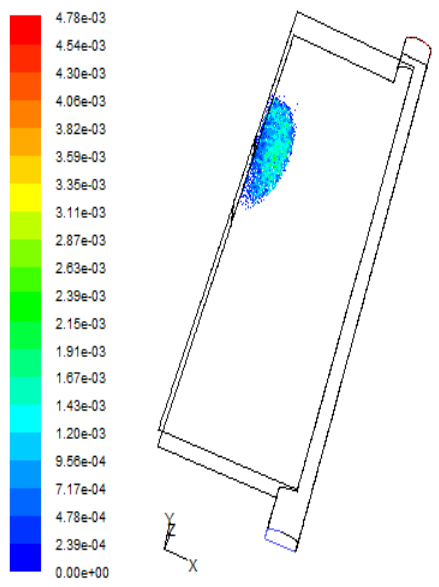

(a) $60 \mathrm{~s}$
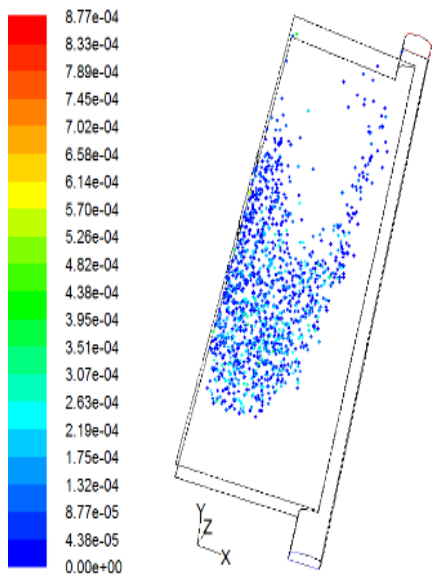

(d) $240 \mathrm{~s}$
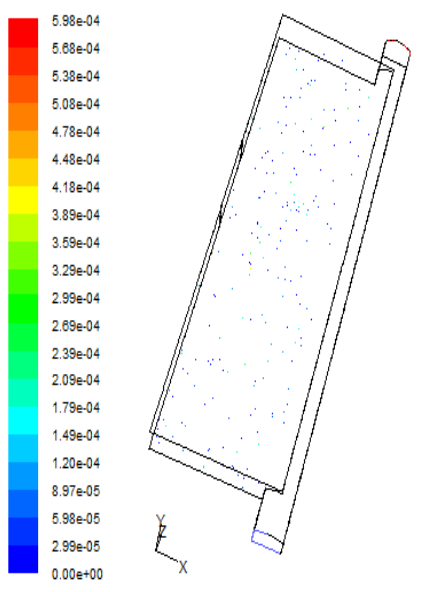

(g) $1200 \mathrm{~s}$
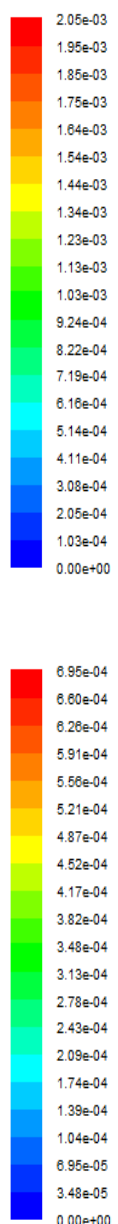

(e) $300 \mathrm{~s}$
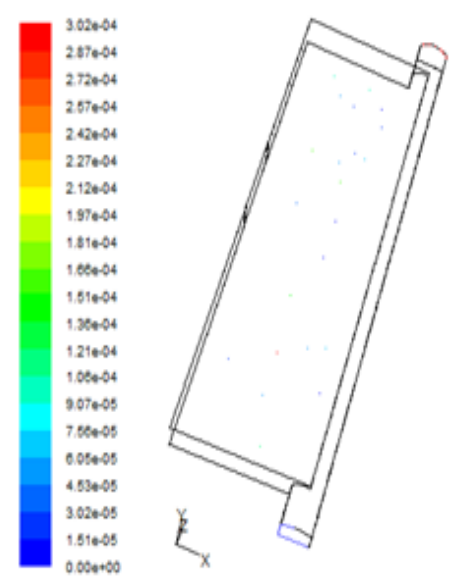

(h) $2400 \mathrm{~s}$

(b) $120 \mathrm{~s}$

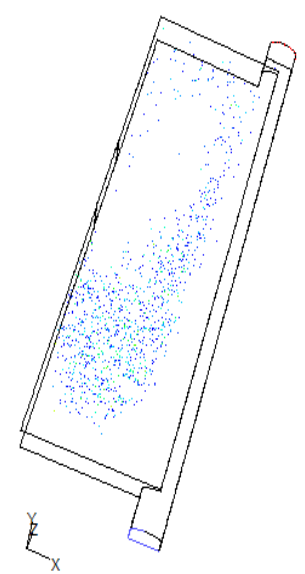

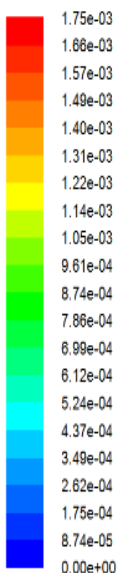

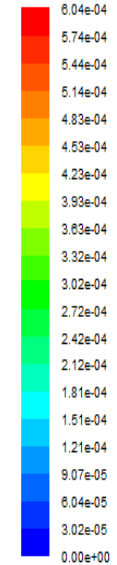

(c) $180 \mathrm{~s}$

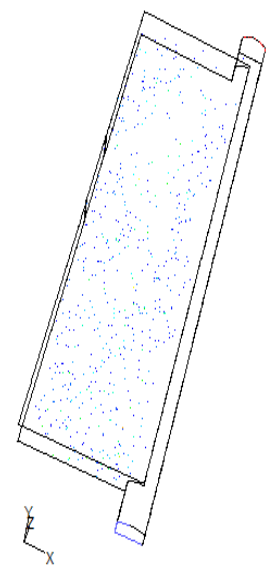

(f) $600 \mathrm{~s}$
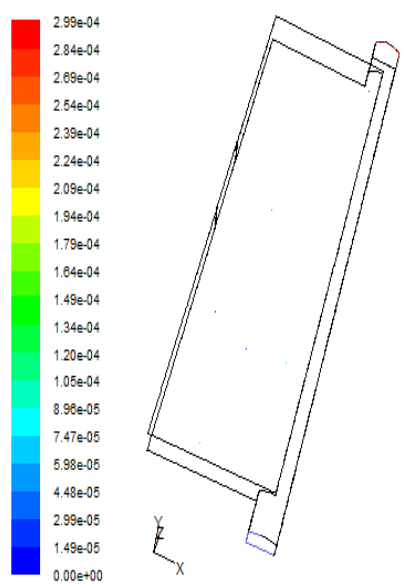

(i) $3600 \mathrm{~s}$

Figure 3. Changes in dust concentration in flat chambers 
(1) In the blasting, dust sprayed into flat chambers from the working face. Within $60 \mathrm{~s}$ from the end of blasting, dust concentration near the face reached a high level, which was approximate $4.78 \times 10^{-3} \mathrm{~kg} / \mathrm{m}^{3}$.

(2) From $120 \mathrm{~s}$ to $300 \mathrm{~s}$, dust was influenced by the flow in the reflux flow boundary and gradually moved from the topleft corner to the bottom-left corner. Since flow velocity in the bottom-left slowed down, a large portion of dust became sediment and was captured by side walls and floors. Ventilation in the bottom-left zone was considerably difficult, resulting in high dust concentrations in this zone, which reached up to $6.95 \times 10^{-4} \mathrm{~kg} / \mathrm{m}^{3}$. From $300 \mathrm{~s}$ to $600 \mathrm{~s}$, due to diffusion of dust and the influence of the reflux flow, dust began circulating in the reflux flow zone, and some of the dust was exhausted through the circulation between the jet flow and reflux flow.

(3) From $600 \mathrm{~s}$ to $2400 \mathrm{~s}$, dust was in the process of circulation exhaust. Dust in main flow was separated to two portions. One portion of dust was directly carried out of the chamber by the main flow, while another portion was carried back into the reflux flow and revolved in a circulating flow. When this dust got close to the main flow, a portion was carried out of the chamber by the main flow, while the rest was carried back to reflux. The circulation lasted for a long time. Most of the dust involved in circulation flow was respirable dust, since the particle size and weight of respirable dust were very small, resulting in a long period of suspension in chambers and was easily affected by fluctuating air flow. At $3600 \mathrm{~s}$, most of the dust was exhausted from chambers and dust concentration was low enough to meet the requirements of working in the mine.

\subsection{Changes in Dust Concentration at Different Flow Velocities}

Based on engineering monitoring and theory analysis, mean flow velocity in intake airways was one of the main factors affecting dust concentration in flat chambers. To study the relevance between mean flow velocity in intake airways and dust concentration in flat chambers, numerical simulations were carried out with variables controlled. In numerical simulations, flow velocity in the intake airway was separately set at $1.0 \mathrm{~m} / \mathrm{s}, 1.5 \mathrm{~m} / \mathrm{s}, 2.0 \mathrm{~m} / \mathrm{s}, 2.5 \mathrm{~m} / \mathrm{s}$ and $3.0 \mathrm{~m} / \mathrm{s}$ while other factors remained the same. Based on the theory of coupling between particle phase and continuous phase, processes of dust exhaust were simulated in a stochastic trajectory model. The results are shown in Figure 4.

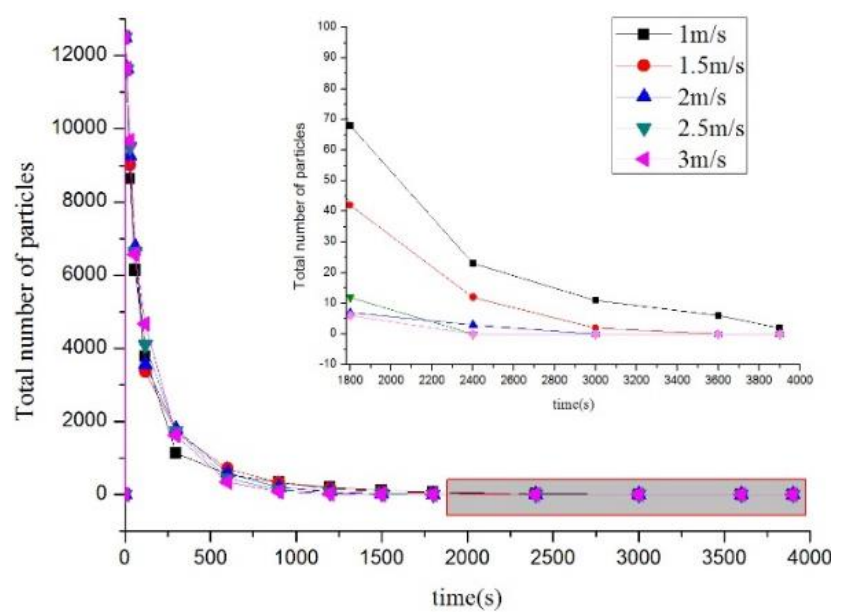

Figure 4. Dust concentration distributions in different flow velocities
Figure 4 shows the following characteristics that were found.

(1) When mean flow velocity in the chamber ranged from $1.0 \mathrm{~m} / \mathrm{s} \sim 3.0 \mathrm{~m} / \mathrm{s}$, increases in mean flow velocity resulted in an apparent decrease in dust mean concentration and dust exhaust time.

(2) The increase in flow velocity accelerated diffusion and dust exhaust, however, it may also have led to reentrainment of dust. In simulations, since flow velocity did not reach reentrainment speed, the increase in flow velocity accelerated diffusion and dust exhaust.

To reach a satisfying exhaust effect in a flat chamber, flow velocity in the intake airways should be kept in a range which both ensured dust exhaust and avoided reenrtainment of dust.

\section{EXPERIMENTS}

\subsection{Test points}

According to the principal of similarity, test points were set in the experiment model to measure flow velocity and dust concentrations. Values of flow velocity and dust concentrations were measured three times in each test point and the mean value was obtained for analysis.

\subsubsection{Test points for flow velocity measurement}

Based on the geometric size of flat chambers and the theory of jet flow field, ten cross sections were selected in the experiment model. In each cross section, test points for flow velocity measurement were set at a form of $3 \times 4$ (three rows and four columns). Locations of test points are shown in Figure 5.

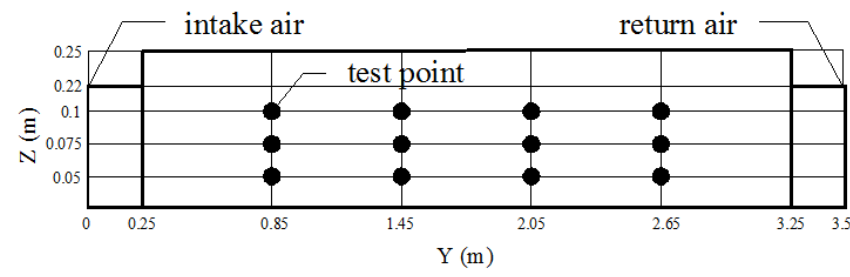

Figure 5. Test points for flow velocity measurement

\subsubsection{Test points for dust concentration measurement}

Four cross sections were selected in the experiment model. In each cross section, test point for dust concentration measurement were set at a form of $3 \times 4$ (three rows and four columns), which were similar to the locations of test points for flow velocity measurement. In each cross section, horizontal distances between columns were separately 0.05 $\mathrm{m}, 0.3 \mathrm{~m}, 0.55 \mathrm{~m}$ and $0.8 \mathrm{~m}$. Distances between adjacent cross sections were $0.6 \mathrm{~m}$. Locations of test points are shown in Figure 6.

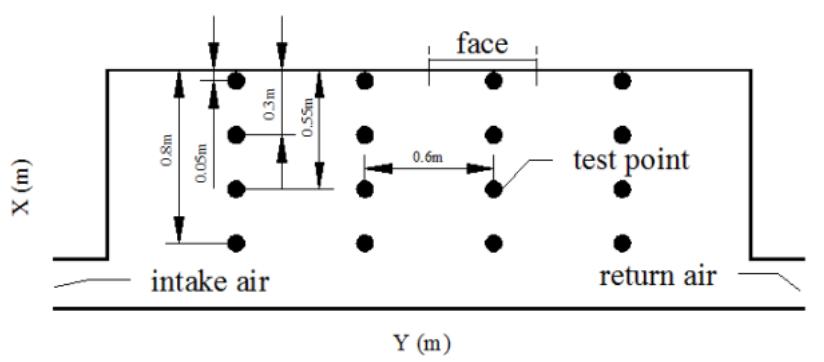

Figure 6. Arrangement of test points of dust concentration 


\subsection{Flow field distributions}

To study flow field distributions, the plane $\mathrm{Z}=0.075 \mathrm{~m}$ was chosen for analysis and intake airways flow velocity was set as $1.0 \mathrm{~m} / \mathrm{s}$ in experiments. In Figure 7, distributions in intersecting lines between plane $\mathrm{Z}=0.075 \mathrm{~m}$ and cross sections $\mathrm{Y}=0.85 \mathrm{~m}, \mathrm{Y}=1.45 \mathrm{~m}, \mathrm{Y}=2.05 \mathrm{~m}, \mathrm{Y}=2.65 \mathrm{~m}$ were showed and the following characteristics were observed.

(1) With distance from the side wall decreasing, dust concentrations in intersecting lines between plane $\mathrm{Z}=0.075 \mathrm{~m}$ and cross sections $\mathrm{Y}=0.85 \mathrm{~m}, \mathrm{Y}=1.45 \mathrm{~m}$ decreased. Within a distance from $0 \mathrm{~m}$ to $0.6 \mathrm{~m}$, flow velocity was closed to 0 $\mathrm{m} / \mathrm{s}$, where ventilation effects were extremely poor. In cross sections $\mathrm{Y}=2.05 \mathrm{~m}$, and $\mathrm{Y}=2.65 \mathrm{~m}$, flow velocity initially increased, then decreased, then increased again in the end. In a distance from $0.3 \mathrm{~m}$ to $0.5 \mathrm{~m}$, flow velocity was below 0.1 $\mathrm{m} / \mathrm{s}$. Ventilation was still very difficult in this zone. In a distance from $0.5 \mathrm{~m}$ to $0.9 \mathrm{~m}$, flow velocity in four cross sections all rapidly increased beyond $0.6 \mathrm{~m} / \mathrm{s}$.

(2) In cross section $Y=0.85$, air flow was in a reverse direction from $0 \mathrm{~m}$ to $0.65 \mathrm{~m}$, and was in an opposite direction from $0.65 \mathrm{~m}$ to $0.90 \mathrm{~m}$. In cross section $\mathrm{Y}=1.45 \mathrm{~m}$, air flow was in a reverse direction from $0 \mathrm{~m}$ to $0.55 \mathrm{~m}$, and was in an opposite direction from $0.55 \mathrm{~m}$ to $0.90 \mathrm{~m}$. In cross section $\mathrm{Y}=2.05 \mathrm{~m}$, air flow was in a reverse direction from $0 \mathrm{~m}$ to $0.45 \mathrm{~m}$, and was in an opposite direction from $0.45 \mathrm{~m}$ to 0.90 $\mathrm{m}$. In cross section $\mathrm{Y}=2.65 \mathrm{~m}$, air flow was in a reverse direction from $0 \mathrm{~m}$ to $0.40 \mathrm{~m}$, and was in an opposite direction from $0.40 \mathrm{~m}$ to $0.90 \mathrm{~m}$.

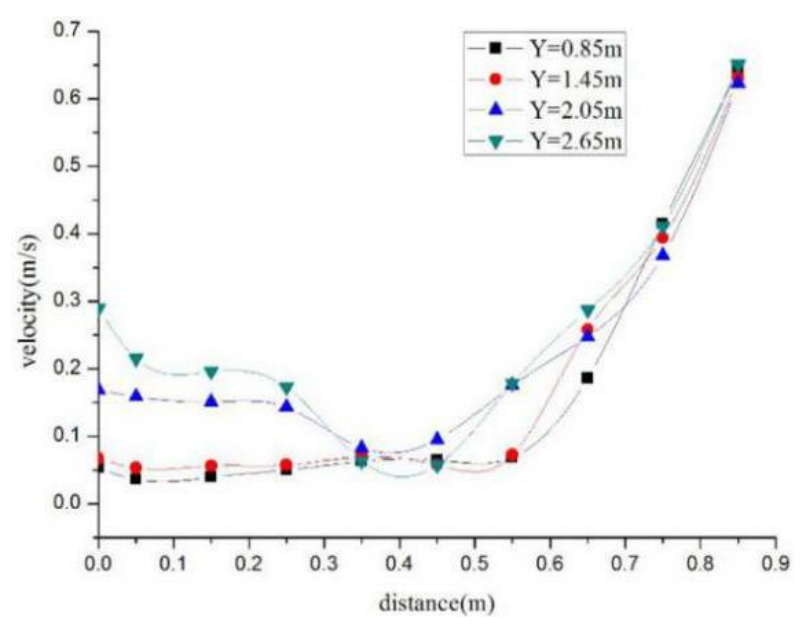

Figure 7. Flow velocity in plane $\mathrm{Z}=0.075 \mathrm{~m}$

\subsection{Dust concentration distributions}

Dust concentration distributions were measured in a flat chamber model while flow velocity in intake airways was 1.0 $\mathrm{m} / \mathrm{s}$. Distributions of maximum dust concentration in different cross sections are shown in Figure 8.

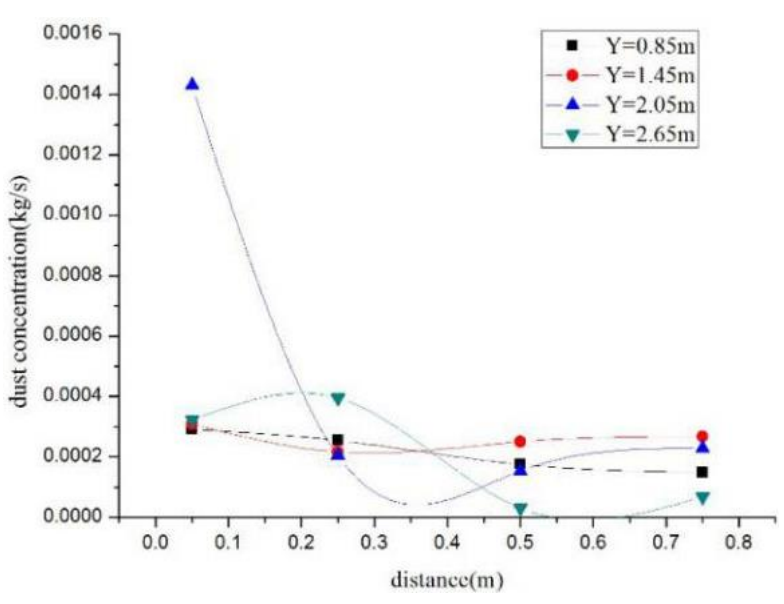

Figure 8. Dust concentration in sections

Figure 8 shows the following observed characteristics.

(1) In blasting, dust jetted into the chamber from faces, which resulted in the highest degree of dust concentration being around faces. Then, large sized grains of dust dropped quickly due to effect of gravity and was captured by side walls and floors. Respirable dust suspended in chambers for a long time since low drop velocity resulted from small sized grains.

(2) Dust concentrations undulated and appeared to be trending downward in various cross sections with coordinates $\mathrm{Y}=1.45 \mathrm{~m}, \mathrm{Y}=2.05 \mathrm{~m}, \mathrm{Y}=2.65 \mathrm{~m}$, which indicated that dust could be divided as two major portions. One portion was exhausted by the main flow resulting in a decrease in the mean concentration of dust. The other portion recirculated in chambers, which contributed to undulating concentration levels. Dust concentration distributions in the cross section with coordinate $\mathrm{Y}=0.85 \mathrm{~m}$ appeared to slowly decline, which resulted from slow flow velocity and great ventilation difficulty in the lee side corner.

\subsection{Comparison between experiments and numerical simulations}

Parameters and boundary conditions in numerical simulations were coherent with experiment models. Intersecting lines between different cross sections and plane $\mathrm{Z}=1.5 \mathrm{~m}$ were set as base lines. Flow velocity and dust concentration distributions in based lines were compared, as shown in Figure 9.

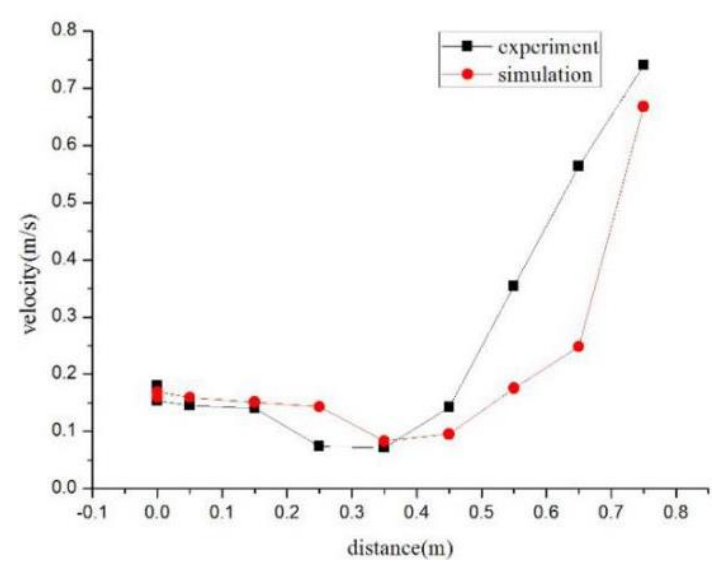

Figure 9. Flow velocity in experiments and numerical simulations 


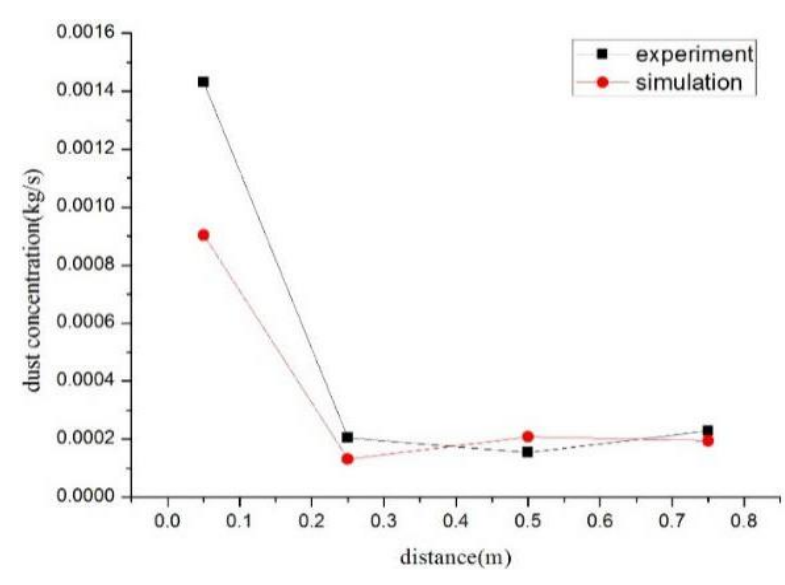

Figure 10. Dust concentration in experiments and numerical simulations

The following characteristics were observed, as Figures 9 and 10 show. Flow velocity and dust concentrations in experiments and numerical simulations along based line were consistent with each other, showing the same distributions and trends. Deviations resulted from experiment

measurements, modeling and parameter sets. Comparisons indicated that the discrete phase model was appropriate to simulate the dust motion process in flat chambers and simulation results matched well with reality.

\section{CONCLUSIONS}

(1) Flow components in flat chambers included jet flow and reflux flow. Flow velocity in the jet flow zone was comparatively high and ventilation effects were better. Flow velocity in the reflux flow zone was comparatively low and ventilation effects were much poorer. The results indicate that parameters were properly set in the experiment model and the results matched well with reality.

(2) Flow velocity in intake airways significantly affected dust motion. An increase in flow velocity would decrease dust exhaust time while a decrease in flow velocity increased dust exhaust time. Furthermore, effects of the flow field on dust motion would increase resulting from a raise in flow velocity.

(3) Dust concentrations undulated and appeared to be trending downward in cross sections with an increasing distance away from the face. This indicates that dust exhaust in the reflux flow zone mainly depended on circulation flow between the jet flow and the reflux flow. A circulation flow with a small area and slow flow velocity resulted in great ventilation difficulty in the corner of lee side.

\section{ACKNOWLEDGEMENTS}

This research was supported by the China Postdoctoral Science Foundation project (2015M582779XB \& 2016M592895XB).

\section{REFERENCES}

[1] Y. M. Wang, C. C. Luan, et al., "Research on flow components in flat chamber," Industrial Safety and Environmental Protection, no. 5, pp. 19-25, 1983.
[2] Y. M. Wang, C. C. Luan, et al., "The calculation of air quantity required for flat-chamber stope," Nonferrous Metals, vol. 37, no. 1, pp. 26-32, 1985.

[3] C. Wu, "Numerical analysis of flow field and smoke exhaust model in flat chambers," Nonferrous Mines, no. 1, pp. 52-53, 1990.

[4] F. Li, Z. Y. Sa, Y. Wang, et al., "Study on the dust concentration distribution and migration in flat-type chamber stope based on fluent software." Mining Research and Development, vol. 30, no. 5, pp. 77-80, 2010.

[5] Y. P. Qin, M. M. Zhang, L. J. Cui, et al., "Numerical simulation of dust migration and study on dust removal modes with the forced ventilation shunt in a fully mechanized workface," Journal of University of Science and Technology Beijing, vol. 33, no. 7, pp. 790-794, 2011.

[6] W. Niu, Z. A. Jiang, Y. Liu, "Numerical simulation on dust movement regularities at fully-mechanized coal faces and its utilization," Journal of Liaoning Technical University: Natural Science, vol. 29, no. 3, pp. 357-360, 2010.

[7] Y. Liu, Z. A. Jiang, W. Cai, et al., "Numerical simulation of the dust movement rule in fullymechanized coal faces," Journal of University of Science and Technology Beijing, vol. 29, no. 4, pp. 351-353, 2007.

[8] C. H. Shi, S. N. Ou and L. Z. Jin, "A study and analysis on the law of motion of the coal dust," Journal of University of Science and Technology Beijing, 29, no. 2, pp. 1-15, 2007.

[9] C. F. Du, H. Wang, Z. A. Jiang, et al., "Numerical simulations of dust distribution in a fully mechanized excavation face with far-pressing-near-absorption ventilation," Journal of University of Science and Technology Beijing, vol. 32 , no. 8, pp. 957-962, 2010.

[10] X. X. Shi, Z. A. Jiang, S. Y. Zhou, et al., "Experimental study on dust distribution regularity of fully mechanized mining face," Journal of China Coal Society, vol. 33, no. 10, pp. 1117-1121, 2008.

[11] J. S. Chen, Z. A. Jiang and L. Jian, "Experimental research on dust distribution and its influencing factors in belt conveyer roadway," Journal of China Coal Society, vol. 39, no. 1, pp. 135-140, 2014.

[12] J. S. Chen, Z. A. Jiang and M. Wang, "Numerical simulation and experimental research on dust concentration distribution in belt conveyer roadway," Journal of Hunan University, vol. 42, no. 6, pp. 127134, 2015.

[13] C. S. Lin, R. W. Moutton and G. L. Puttnam, "Mass Transfer between solid wall and Fluidi stream," Ind. Eng. Chem., vol. 45, pp. 636, 1953.

[14] S. K. Friendlander and H. F. Johnstone, "Deposition of suspended particles from turbulent gas streams," Ind. Eng. Chem., vol. 49, pp. 1151, 1957.

[15] S. K. Beal, "Deposition of particles in turbulent flow on channel or pipe walls," Nuclear Sci. \& Eng, vol. 40, pp. 1-11, 1970.

[16] Y. M. Wang, Aerodynamic Applied in Mines and Ventilation System, Beijing: Metallurgical Industry Press, 1994, pp. 83-93.

[17] X. Z. Wang, Z. A. Jiang, S. W. Wang, et al., "Numerical simulation of dust concentration distributions in coal road driving," Journal of China Coal Society, vol. 32, no. 4, pp. 386-390, 2007. 